\title{
Interferência de plantas daninhas na qualidade e produtividade do grão-de-bico
}

\author{
Matheus Ferreira França Teixeira ${ }^{1}$, Evandro Marcos Biesdorf ${ }^{1}$, Daniel Teixeira Pinheiro ${ }^{1}$, \\ Tiago Teixeira Viana Barros ${ }^{1}$, Erick Iglesias ${ }^{1}$
}

\footnotetext{
${ }^{1}$ Universidade Federal de Viçosa - UFV, Campus de Viçosa, Viçosa, Minas Gerais, Brasil. E-mail: teixeiramff@gmail.com, evandromarcospva@hotmail.com, pinheiroagroufv@gmail.com, tiago.barros.agronomia@gmail.com, erick.iglesias@ufv.br
}

Recebido: 05/04/2017; Aceito: 20/05/2017

\section{RESUMO}

O cultivo de grão-de-bico (Cicer arietinum L.) tem sido dificultado devido às interferências das plantas daninhas. Objetivou-se verificar o efeito da interferência de seis diferentes espécies invasoras (Bidens pilosa, Commelina benghalensis, Eleusine indica, Ipomoea grandifolia, Uruchloa brizantha e Uruchloa ruziziensis) na qualidade e produtividade de dois cultivares de grão-de-bico (BRS Aleppo e FLIP 86-77c). A interferência das plantas daninhas reduziu o período vegetativo de ambos os cultivares. A espécie Uruchloa ruziziensis influenciou negativamente o número de vagens do cultivar BRS Aleppo sugerindo ser prejudicial ao cultivo. Além disso, os resultados indicaram que há relação entre o período de convivência e o nível de infestação no número de grãos por vagem e peso de cem grãos. Contudo, apesar de todas as espécies daninhas terem afetado a produtividade dos cultivares, tal efeito foi mais sobressalente no cultivar FLIP 86-77c, sobretudo na presença de $C$. benghalensis, $U$. brizantha e $U$. ruzizinsis. O teor de nutrientes no grão variou de acordo com a espécie daninha analisada. $C$. benghalensis, E. indica, U. brizantha e $U$. ruziziensis apresentam maior potencial de competição, sendo responsáveis pelos maiores danos na produtividade e nas características qualitativas dos grãos.

Palavras-chave: Cicer arietinum L., competição, produção.

\section{Weed interference on quality and yield of chickpea}

\begin{abstract}
Cultivation of chickpea (Cicer arietinum L.) has been hampered by weed interference. The objective of this study was to investigate the effect of six different weed species (Bidens pilosa, Commelina benghalensis, Eleusine indica, Ipomoea grandifolia, Uruchloa brizantha and Uruchloa ruziziensis) on the quality and yield of two chickpea cultivars (BRS Aleppo and FLIP 86-77c). Interference with weeds reduced the vegetative period of both cultivars. The Uruchloa ruziziensis negatively influenced the number of pods of the cultivar BRS Aleppo suggesting to be detrimental to the crop. In addition, results indicated that there is a relationship between the period of cohabitation and infestation level on number of grains per pod and weight of one hundred grains. However, although all weeds affected the yield of cultivars, this effect was more prominent in FLIP 86-77c, especially in the presence of $C$. benghalensis, $U$. brizantha and $U$. ruzizinsis. The nutrient content in the grain varied according to the analyzed weed species. $C$. benghalensis, E. indica, $U$. brizantha and $U$. ruziziensis present greater competition potential, being responsible for the greater effects on productivity and on the qualitative characteristics of the grains.
\end{abstract}

Key words: Cicer arietinum L., competition, production 


\section{Introdução}

O grão-de-bico (Cicer arietinum L.) é uma das leguminosas mais produzidas do mundo (HOSSAIN et al., 2010). Trata-se de uma leguminosa de inverno de alta rusticidade, alto valor nutritivo e melhor disponibilidade de ferro (BRAZACA; SILVA, 2003). Em 2011, sua produção global foi estimada em uma área de 13 milhões de hectares, totalizando 11,6 milhões de toneladas produzidas. Nesse contexto, o Irã figura como principal produtor, sendo responsável por $76 \%$ da produção total mundial (FAOSTAT, 2016).

Apesar da grande quantidade ocupada por essa cultura no mundo, no Brasil, o principal obstáculo para a expansão da produção dessa leguminosa se refere à baixa capacidade de competição com plantas daninhas (WHISH et al., 2002), resultando em perdas de rendimento consideráveis em função do nível de infestação e da espécie predominante (BHAN; KUKULA, 1987).

De acordo com Zanatta et al. (2006), as perdas de produtividade podem ocorrer diretamente, na medida em que as plantas daninhas competem pelos recursos do meio, como água, luz e nutrientes, comprometendo a qualidade final do produto, ou indiretamente como hospedeiras de pragas e doenças comprometendo as práticas culturais e a colheita. Os efeitos da interferência variam de acordo com o nível de infestação, condições edafoclimáticas, características do cultivar e do período de convivência (AGOSTINETTO et al., 2001).

Soma-se a isso o fato de que na cultura do grão-debico os efeitos deletérios da convivência com as plantas daninhas são agravados principalmente quando se tratam de daninhas anuais de folhas largas, dada a semelhança no padrão de crescimento com a leguminosa em questão. Dessa forma, poucos são os estudos que cuidaram em verificar o grau de interferência que as principais plantas daninhas encontradas nas áreas produtivas brasileiras ocasionam à espécie.

Portanto, considerando escassos os estudos relacionados à interferência das plantas daninhas na cultura do grão-de-bico, o presente trabalho objetivou verificar o efeito da convivência de seis plantas daninhas (Bidens pilosa, Commelina benghalensis, Eleusine indica, Ipomoea grandifolia, Uruchloa brizantha e Uruchloa ruziziensis) na qualidade e produtividade de dois cultivares de grão-de-bico.

\section{Material e Métodos}

$\mathrm{O}$ experimento foi realizado em local sem cobertura localizado na área experimental pertencente ao Departamento de Fitotecnia da Universidade Federal de Viçosa, nos meses de dezembro de 2015 a abril de 2016.

Os dados referentes às temperaturas média e precipitação ao longo do ensaio foram coletados a partir da plataforma do INMET (Figura 1). Os meses com maior precipitação pluviométrica foram dezembro e janeiro com valores de 240 e $348 \mathrm{~mm}$, respectivamente. As temperaturas máxima e mínima se mantiveram constantes ao longo da duração do experimento.

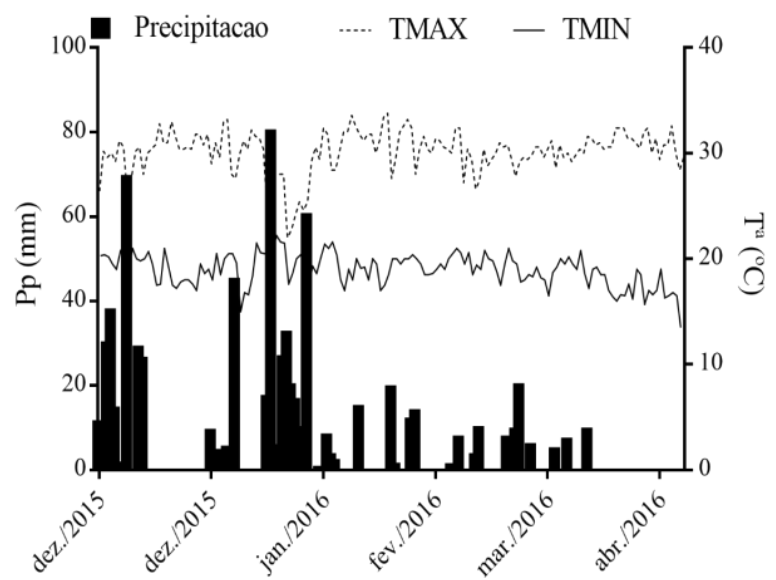

Figura 1. Dados meteorológicos de precipitação $(\mathrm{mm})$ e temperatura $\left({ }^{\circ} \mathrm{C}\right)$ durante o período de dezembro/2015 até abril/2016 referentes à cidade de Viçosa, MG.

Foram utilizados vasos plásticos de $20 \mathrm{~L}$ contendo solo como substrato (Latossolo Vermelho-Amarelo) coletado na camada de 0-20 cm, caracterizado quimicamente, conforme preceitos da Embrapa (1997). Os principais resultados da análise química do solo são mostrados na Tabela 1.

Os tratamentos foram dispostos em delineamento inteiramente casualizado, em esquema fatorial $6 \times 2$, sendo seis espécies de plantas daninhas: capim-pé-degalinha (Eleusine indica), braquiária-brizantha (Urochloa brizantha), braquiária-ruziziensis (Urochloa ruziziensis), corda-de-viola (Ipomoea grandifolia), picão-preto (Bidens pilosa) e trapoeraba (Commelina benghalensis) e dois cultivares de grão-de-bico: BRS Aleppo e FLIP 86-77c, com quatro repetições.

Tabela 1. Características químicas do solo utilizado no preparo do substrato para enchimento dos vasos.

\begin{tabular}{|c|c|c|c|c|c|c|c|c|c|c|c|c|}
\hline $\mathrm{pH}$ & $\mathrm{P}$ & $\mathrm{K}$ & $\mathrm{Ca}$ & $\mathrm{Mg}$ & $\mathrm{Al}$ & $\mathrm{H}+\mathrm{Al}$ & SB & (T) & V & $\mathrm{m}$ & MO & p-rem \\
\hline & \multicolumn{3}{|c|}{$\left(\mathrm{mg} \mathrm{dm}^{-3}\right)$} & \multicolumn{5}{|c|}{ 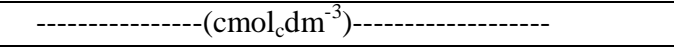 } & \multicolumn{3}{|c|}{$---(\%)----$} & $\left(\mathrm{mg} \mathrm{L}^{-1}\right)$ \\
\hline 5,4 & 1,2 & 30 & 0,3 & 0,3 & 0,0 & 3,1 & 3,14 & 17,64 & 18,0 & 0,0 & 1,55 & 23,9 \\
\hline
\end{tabular}


Antes da semeadura foram realizados testes de germinação, a fim de se caracterizar o potencial germinativo das espécies. Foram verificados valores superiores a $90 \%$ de germinação para todos as espécies avaliadas. Em seguida, as sementes foram tratadas com fungicida carbendazim tiram $(30 \mathrm{~g}+70 \mathrm{~g}$ i.a. por 100 $\mathrm{kg}$ de sementes).

A adubação de semeadura foi realizada de acordo com a análise do solo e as necessidades da cultura, correspondendo a $350 \mathrm{~kg} \mathrm{ha}^{-1}$ da fórmula NPK (02-2018). A semeadura foi feita diretamente nos vasos, de modo que em cada unidade experimental haviam três plantas daninhas e três plantas de grão-de-bico.

Durante a condução do experimento foram avaliados os números de dias antes e pós antese das cultivares de grão-de-bico. A colheita e a determinação do ciclo total da cultura foram feitas quando os grãos apresentavam $16 \%$ de umidade. Nesta ocasião foram avaliados o número de vagens por planta (NVP); número de grãos por vagem (NGV); peso de cem grãos (PCG) (g), produtividade de grãos por planta (PG) $\left(\mathrm{g} \mathrm{pl}^{-1}\right)$. Determinou-se ainda os teores de proteína dos grãos pelo método de Kjeldahl (1984) carboidratos (DETMANN; VALADARES FILHO, 2010), cálcio, fosforo e potássio (JORGENSEN, 1977).

Os dados obtidos foram submetidos à análise de variância e, em caso de significância, as médias foram comparadas pelo teste de Tukey a 5\% utilizando-se o software GraphMap Prism.

\section{Resultados e Discussão}

A interferência das plantas daninhas reduziu o período vegetativo de ambos os cultivares (Tabela 2), sendo essa redução mais acentuada pela convivência com $U$. brizantha e $C$. benghalensis para os cultivares BRS Aleppo e FLIP 86-77c, respectivamente. O ciclo total dos cultivares diferiu significativamente da testemunha para o cultivar BRS Aleppo em convivência com as plantas $C$. benghalensis, E. indica, U. brizantha e U. ruziziensis. Para o cultivar FLIP 86-77c seu ciclo total foi mais afetado pela interferência das plantas $C$. benghalensis, E. indica e U. ruziziensis (Tabela 2).

A convivência das plantas daninhas pode interferir no período vegetativo e de maturação dos grãos, alterando o número de vagens por planta e, consequentemente diminuindo a produtividade da cultura. A fase vegetativa do grão-de-bico dura aproximadamente 40 a 80 dias, dependendo da variedade, localização, temperaturas e condições de umidade do solo (VAN DER MAESEN, 1984). No presente estudo foi observada diferença significativa no ciclo vegetativo de ambas as cultivares de grão-de-bico, quando em convivência com as plantas daninhas, mantendo-se dentro do esperado (40 a 80 dias), entretanto essa redução na fase vegetativa pode ser um dos possíveis fatores responsáveis pela redução na produtividade dos grãos.

Não houve diferença significativa para o número de vagens por planta entre as cultivares em convivência com as plantas daninhas avaliadas, exceto para Uruchloa ruziziensis, a qual a cultivar BRS Aleppo mostrou-se mais sensível (Tabela 3). Além disso, em ambas as cultivares observou-se que os menores valores de vagens por planta ocorreram na presença das braquiárias: Uruchloa brizantha e U. ruziziensis.

Tabela 2. Dias antes da antese, dias após antese e ciclo total dos cultivares de grão-de-bico (Cicer arietinum L.) BRS Aleppo e FLIP 86-77 c em convivência com diferentes espécies de plantas daninhas. Universidade Federal de Viçosa, 2016.

\begin{tabular}{|c|c|c|c|c|}
\hline Cultivar & Planta daninha & Dias antes antese & Dias após antese & Ciclo total \\
\hline \multirow{7}{*}{ BRS Aleppo } & Bidens pilosa & $60 \mathrm{Ba}$ & $75 \mathrm{Aa}$ & $135 \mathrm{ABa}$ \\
\hline & Commelina benghalensis & $50 \mathrm{BCa}$ & $70 \mathrm{Aa}$ & $120 \mathrm{Ba}$ \\
\hline & Eleusine indica & $55 \mathrm{BCa}$ & $75 \mathrm{Aa}$ & $130 \mathrm{Ba}$ \\
\hline & Ipomoea grandifolia & $60 \mathrm{Ba}$ & $72 \mathrm{Aa}$ & $132 \mathrm{ABa}$ \\
\hline & Urochloa brizantha & $47 \mathrm{Ca}$ & $74 \mathrm{Aa}$ & $121 \mathrm{Ba}$ \\
\hline & Urochloa ruziziensis & $50 \mathrm{BCa}$ & 75 Aa & $125 \mathrm{Ba}$ \\
\hline & Testemunha & $80 \mathrm{Aa}$ & $64 \mathrm{Ba}$ & $144 \mathrm{Aa}$ \\
\hline \multirow{7}{*}{ FLIP 86-77c } & Bidens pilosa & $60 \mathrm{BCa}$ & $73 \mathrm{Aa}$ & $133 \mathrm{Ba}$ \\
\hline & Commelina benghalensis & $45 \mathrm{Cb}$ & $70 \mathrm{ABa}$ & $115 \mathrm{Cb}$ \\
\hline & Eleusine indica & $50 \mathrm{BCb}$ & $70 \mathrm{ABa}$ & $120 \mathrm{Cb}$ \\
\hline & Ipomoea grandifolia & $62 \mathrm{Ba}$ & $72 \mathrm{Aa}$ & $134 \mathrm{ABa}$ \\
\hline & Urochloa brizantha & $48 \mathrm{BCa}$ & $75 \mathrm{Aa}$ & $123 \mathrm{BCa}$ \\
\hline & Urochloa ruziziensis & $48 \mathrm{BCa}$ & $65 \mathrm{Bb}$ & $113 \mathrm{Cb}$ \\
\hline & Testemunha & $80 \mathrm{Aa}$ & $66 \mathrm{Bb}$ & $146 \mathrm{Aa}$ \\
\hline $\mathrm{CV}(\%)$ & & 2,84 & 2,66 & 2,13 \\
\hline
\end{tabular}

* Na coluna, médias seguidas pela mesma letra minúscula não diferem entre si entre os cultivares e médias seguidas pela mesma letra maiúscula não diferem entre si dentro das cultivares de grão-de-bico pelo teste Tukey a $5 \%$ de probabilidade. 
A possível explicação para a redução no número de vagens é a menor emissão de inflorescências e ao abortamento de flores ocasionado, de acordo com Freitas et al. (2009), pela competição com as plantas daninhas. Em estudo realizado por Santos et al. (2003) com manejo de nitrogênio em feijão-comum, foi verificado que o número de vagens por planta é um componente altamente correlacionado com a produtividade. Silva et al. (2008), com o objetivo de determinar os efeitos de diferentes densidades de plantas daninhas (baixa, média e alta) sobre os componentes de rendimento da soja, observaram que com relação aos componentes de produção, o número de vagens por planta foi o mais afetado pela competição, com reduções de até $58 \%$ na área de baixa infestação, $71 \%$ na de média infestação e $78 \%$ na de alta infestação. Apesar de o número de sementes por vagens e peso de 1000 grãos terem reduzido em diferentes proporções nas diferentes densidades de plantas daninhas, os autores relataram que essas respostas não eram as principais responsáveis pelo efeito da competição.

Dessa forma, os resultados indicaram que há relação entre o período de convivência e o nível de infestação sobre os componentes de produção da soja (número de vagens/planta, número de sementes/vagem e peso de mil grãos).

Quanto ao número de grãos por vagem e o peso de cem grãos, não foi observada diferença significativa entre as cultivares. Ambas apresentaram perdas semelhantes no número de grãos por vagem, sendo mais afetadas na presença de Commelina benghalensis (trapoeraba), Eleusine indica (pé-de-galinha), $U$. brizantha e $U$. ruziziensis. De maneira análoga, observou-se perdas similares para as cultivares quanto ao peso de 100 grãos. As cultivares apresentaram redução mais acentuada quando em convivência com $C$. benghalensis, U. brizantha e U. ruzizinsis (Tabela 3).

Em experimento com feijão-caupi, Freitas et al. (2009) avaliaram a interferência de plantas daninhas por um período de 60 dias na cultura, e observaram a redução de até $90 \%$ no rendimento de grãos e, aproximadamente, $83 \%$ no número de vagens por planta em relação à testemunha mantida livre de competição. Entretanto, não observaram diferença significativa para o peso de 100 grãos de feijão-caupi cultivado sob interferência de plantas daninhas em contraste à testemunha (livre de infestação).

Apesar de todas as espécies daninhas terem afetado a produtividade das cultivares, esse efeito foi mais sobressalente no cultivar FLIP 86-77c, sobretudo na presença de $C$. benghalensis, $U$. brizantha e $U$. ruzizinsis. Para a cultivar BRS Aleppo, os principais resultados foram observados com as mesmas daninhas supracitadas, incluindo-se a E. Indica (Tabela 3).

Efeito semelhante foi observado por Cerna e Valdez (1987) na cultura do feijão-comum (Phaseolus vulgaris L.), cultivar Pirata 2, sob vários níveis de infestação de B. pilosa e Sorghum halepense. Houve uma redução na produtividade proporcional ao número de plantas daninhas por unidade de área, com redução de 48,9\% quando em convivência com B. pilosa e $43 \%$ para $S$. halepense. Além disso, as plantas daninhas promoveram redução significativa da matéria seca total e número de vagens por planta no feijoeiro.

Tabela 3. Número de vagens por planta (NVP), número de grãos por vagem (NGV), peso de cem grãos (PCG) (g) e produtividade de grãos por (PG) $\left(\mathrm{g} \mathrm{pl}^{-1}\right)$ dos cultivares de grão-de-bico (Cicer arietinum L.) BRS Aleppo e FLIP 86-77c em convivência com diferentes espécies de plantas daninhas. Universidade Federal de Viçosa, 2016.

\begin{tabular}{|c|c|c|c|c|c|}
\hline \multirow{2}{*}{ Cultivar } & \multirow{2}{*}{ Planta Daninha } & \multirow{2}{*}{ NVP } & \multirow{2}{*}{ NGV } & PCG & \multirow{2}{*}{$\begin{array}{c}\text { PG } \\
\left(\mathrm{g} \mathrm{pl}^{-1}\right)\end{array}$} \\
\hline & & & & (g) & \\
\hline \multirow{7}{*}{ BRS Aleppo } & Bidens pilosa & $16 \mathrm{Ba}$ & $2 \mathrm{Aa}$ & $46,1 \mathrm{ABa}$ & $13,43 \mathrm{Ba}$ \\
\hline & Commelina benghalensis & $9 \mathrm{Ca}$ & $1 \mathrm{Ba}$ & $37,7 \mathrm{Ca}$ & $3,23 \mathrm{Ca}$ \\
\hline & Eleusine indica & $11 \mathrm{BCa}$ & $1 \mathrm{Ba}$ & $42,6 \mathrm{Ba}$ & $4,02 \mathrm{Ca}$ \\
\hline & Ipomoea grandifolia & $14 \mathrm{Ba}$ & $2 \mathrm{Aa}$ & 46,3 Aba & $11,90 \mathrm{Ba}$ \\
\hline & Urochloa brizantha & $2 \mathrm{Da}$ & $1 \mathrm{Ba}$ & $35,8 \mathrm{Ca}$ & $1,23 \mathrm{Ca}$ \\
\hline & Urochloa ruziziensis & $4 \mathrm{Db}$ & $1 \mathrm{Ba}$ & $40,4 \mathrm{BCa}$ & $2,42 \mathrm{Ca}$ \\
\hline & Testemunha & $23 \mathrm{Aa}$ & $2 \mathrm{Aa}$ & $48,2 \mathrm{Aa}$ & $20,66 \mathrm{Aa}$ \\
\hline \multirow{7}{*}{ FLIP $86-77 \mathrm{c}$} & Bidens pilosa & $17 \mathrm{Ba}$ & $2 \mathrm{Aa}$ & $48,2 \mathrm{Aa}$ & $13,22 \mathrm{Ba}$ \\
\hline & Commelina benghalensis & $10 \mathrm{Ca}$ & $1 \mathrm{Ba}$ & $36,7 \mathrm{Ca}$ & $2,83 \mathrm{CDa}$ \\
\hline & Eleusine indica & $11 \mathrm{Ca}$ & $1 \mathrm{Ba}$ & $42,0 \mathrm{Ba}$ & $3,96 \mathrm{Ca}$ \\
\hline & Ipomoea grandifolia & $15 \mathrm{BCa}$ & $2 \mathrm{Aa}$ & 46,0 Aba & $11,04 \mathrm{Bb}$ \\
\hline & Urochloa brizantha & $4 \mathrm{Da}$ & $1 \mathrm{Ba}$ & $33,5 \mathrm{Ca}$ & $0,57 \mathrm{Da}$ \\
\hline & Urochloa ruziziensis & $7 \mathrm{CDa}$ & $1 \mathrm{Ba}$ & $39,1 \mathrm{BCa}$ & $1,34 \mathrm{CDb}$ \\
\hline & Testemunha & $25 \mathrm{Aa}$ & $2 \mathrm{Aa}$ & 47,4 Aa & $18,69 \mathrm{Ab}$ \\
\hline CV $(\%)$ & & 3,16 & 1,12 & 7,44 & 8,39 \\
\hline
\end{tabular}

* Na coluna, médias seguidas pela mesma letra minúscula não diferem entre si entre os cultivares e médias seguidas pela mesma letra maiúscula não diferem entre si dentro das cultivares de grão-de-bico pelo teste Tukey a $5 \%$ de probabilidade. 
Bridges et al. (1992) verificaram que a infestação do leiteiro (Euphorbia heterophylla) na soja provocou reduções de 30 a $50 \%$ na produtividade da cultura nas densidades de 12 e 32 plantas $\mathrm{m}^{-2}$. Embora sejam de culturas diferentes, esses trabalhos corroboram com o presente estudo, uma vez que as perdas de produtividade variaram aproximadamente entre 35 e 94\% para a cultivar BRS Aleppo e entre 30 e $97 \%$ para a cultivar FLIP 86-77c, evidenciando a importância do manejo das plantas daninhas para se obter uma produtividade satisfatória.

Observou-se que não houve diferença estatística no percentual de carboidratos, proteínas, cálcio e potássio entre as cultivares tanto em convivência quanto na ausência de plantas daninhas (Tabela 4). Entretanto, os menores valores na concentração de carboidratos, em ambas as cultivares, foram observados na convivência com C. benghalensis, E. indica, U. brizantha e $U$. ruzizienses.

O teor de proteínas do grão-de-bico pode variar de 17 a $24 \%$, podendo chegar ao extremo de $31,5 \%$ de proteínas (WILLIAMS; SINGH, 1987). De acordo com o Instituto Brasileiro de Geografia e Estatística (IBGE), o teor de proteínas varia 18,8 a $21,8 \%$ e de carboidratos de 67,8 a 70\% (IBGE, 1996). Ferreira et al. (2006), ao estudarem a composição centesimal e mineral de grãode-bico irradiados e não irradiados para verificar as alterações provocadas pela cocção, observaram um teor de proteínas de $25,7 \%$ (g/100g) e de 45,4\% (g/100g) de carboidratos nos grãos crus.

Os resultados do presente estudo mostram que o conteúdo de carboidratos obtidos na testemunha e em convivência com as plantas daninhas, encontram-se abaixo do valor de referência do IBGE (1996).

Em relação ao teor de proteínas, houve redução no cultivar BRS Aleppo quando em convivência com $B$. pilosa, $C$. benghalensis e $U$. brizantha. De outro modo, o cultivar FLIP 86-77c apresentou redução no teor protéico apenas na presença de $B$. pilosa e $C$. benghalensis (Tabela 4).

$\mathrm{O}$ valor obtido para testemunha encontra-se dentro do valor de referência do IBGE para a cultivar BRS Aleppo, porém relativamente aquém para a cultivar FLIP 86-77c. A convivência com algumas plantas daninhas gerou perdas no teor de proteínas, no entanto a convivência de ambas as cultivares com B. pilosa e $C$. benghalensis causou perdas no conteúdo protéico abaixo dos valores de referência, apresentando teores de 15 e $16 \%$ para o cultivar BRS Aleppo e 12 e $16 \%$ para a cultivar FLIP 86-77c.

A cultivar BRS Aleppo diferiu estatisticamente em relação à testemunha para a concentração de cálcio apenas na presença com B. pilosa. A convivência com a $U$. brizantha foi a daninha que resultou nos menores valores de teor de cálcio, reduzindo $36,4 \%$ e $34,3 \%$ para a cultivar BRS Aleppo e FLIP 86-77c, respectivamente.

Quanto ao percentual de fósforo, a cultivar BRS Aleppo apresentou valores superiores aos do cultivar FLIP 86-77c. As maiores perdas foram observadas em convivência com B. pilosa $(36,5 \%$ - BRS Aleppo e $32,4 \%$ - FLIP 86-77c) e C. benghalensis (41,8\% - BRS Aleppo e 43,4\% - FLIP 86-77c) (Tabela 4).

Tabela 4. Percentual de carboidratos, proteínas, cálcio, fósforo e potássio das cultivares de grão-de-bico (Cicer arietinum L.) BRS Aleppo e FLIP 86-77c em convivência com diferentes espécies de plantas daninhas.

\begin{tabular}{|c|c|c|c|c|c|c|}
\hline \multirow{2}{*}{ Cultivar } & \multirow{2}{*}{ Plantas daninhas } & Carboidratos & Proteínas & Cálcio & Fósforo & Potássio \\
\hline & & $(\%)$ & $(\%)$ & $(\%)$ & $(\%)$ & $(\%)$ \\
\hline \multirow{7}{*}{ BRS Aleppo } & Bidens pilosa & $56 \mathrm{Aa}$ & $15 \mathrm{Ba}$ & $0,100 \mathrm{Aba}$ & $0,217 \mathrm{Ca}$ & $1,000 \mathrm{Ba}$ \\
\hline & Commelina benghalensis & $43 \mathrm{Ba}$ & $16 \mathrm{Ba}$ & $0,082 \mathrm{Ca}$ & $0,199 \mathrm{Ca}$ & $0,914 \mathrm{BCa}$ \\
\hline & Eleusine indica & $45 \mathrm{Ba}$ & $21 \mathrm{ABa}$ & 0,099 Ba & $0,280 \mathrm{Ba}$ & $1,106 \mathrm{Aa}$ \\
\hline & Ipomoea grandifolia & $53 \mathrm{Aa}$ & $22 \mathrm{Aa}$ & $0,084 \mathrm{Ca}$ & $0,296 \mathrm{ABa}$ & $0,832 \mathrm{Ca}$ \\
\hline & Urochloa brizantha & $40 \mathrm{Ba}$ & $18 \mathrm{Ba}$ & $0,070 \mathrm{Da}$ & $0,232 \mathrm{BCa}$ & $0,813 \mathrm{Ca}$ \\
\hline & Urochloa ruziziensis & $45 \mathrm{Ba}$ & $19 \mathrm{ABa}$ & $0,082 \mathrm{Ca}$ & $0,255 \mathrm{BCa}$ & $0,835 \mathrm{Ca}$ \\
\hline & Testemunha & $57 \mathrm{Aa}$ & $22 \mathrm{Aa}$ & $0,110 \mathrm{Aa}$ & $0,342 \mathrm{Aa}$ & $1,112 \mathrm{Aa}$ \\
\hline \multirow{7}{*}{ FLIP $86-77 \mathrm{c}$} & Bidens pilosa & $51 \mathrm{Aa}$ & $12 \mathrm{Ba}$ & $0,095 \mathrm{Aa}$ & $0,221 \mathrm{Ca}$ & $1,002 \mathrm{Ba}$ \\
\hline & Commelina benghalensis & $41 \mathrm{Ba}$ & $16 \mathrm{Ba}$ & 0,079 Ba & $0,185 \mathrm{Cb}$ & $0,910 \mathrm{BCa}$ \\
\hline & Eleusine indica & $44 \mathrm{Ba}$ & $19 \mathrm{Aa}$ & $0,104 \mathrm{Aa}$ & $0,274 \mathrm{Ba}$ & 1,092 Aba \\
\hline & Ipomoea grandifolia & $53 \mathrm{Aa}$ & $22 \mathrm{Aa}$ & $0,079 \mathrm{Ba}$ & $0,282 \mathrm{ABb}$ & $0,834 \mathrm{Ca}$ \\
\hline & Urochloa brizantha & $41 \mathrm{Ba}$ & $18 \mathrm{ABa}$ & 0,067 Ca & $0,240 \mathrm{BCa}$ & $0,801 \mathrm{Ca}$ \\
\hline & Urochloa ruziziensis & $40 \mathrm{Ba}$ & $18 \mathrm{ABa}$ & $0,080 \mathrm{Ba}$ & $0,250 \mathrm{BCa}$ & $0,837 \mathrm{Ca}$ \\
\hline & Testemunha & $55 \mathrm{Aa}$ & $18 \mathrm{ABa}$ & $0,102 \mathrm{Aa}$ & $0,327 \mathrm{Ab}$ & $1,110 \mathrm{Aa}$ \\
\hline $\mathrm{CV}(\%)$ & & 2,1 & 2,0 & 3,17 & 2,95 & 3,86 \\
\hline
\end{tabular}

* Na coluna, médias seguidas pela mesma letra minúscula não diferem entre si entre as cultivares e médias seguidas pela mesma letra maiúscula não diferem entre si dentro das cultivares de grão-de-bico pelo teste Tukey a $5 \%$ de probabilidade. 
Em relação ao percentual de potássio, em ambas as cultivares foram observadas as maiores reduções na presença de I. grandfolia, $U$. brizantha e $U$. ruziziensis (Tabela 4). Ainda, foi observado um decréscimo variando de 10 a 26,9\% para o cultivar BRS Aleppo e de 9,7 a $27,8 \%$ para a cultivar FLIP 86-77 em convivência com as plantas daninhas, exceto com a espécie E. indica - que não apresentou redução no percentual de potássio (Tabela 4). Carvalho et al. (2010) avaliando o crescimento e nutrição mineral da soja mantida em convivência com densidades crescentes de Euphorbia heterophylla, observaram redução no acúmulo de matéria seca e de macronutrientes à medida em que a convivência foi estabelecida devido à competição da planta daninha pelos nutrientes do solo. As reduções no acúmulo de macronutrientes da soja foram de $85 \%$ para $\mathrm{N}$; $85 \%$ para $\mathrm{P}$; de $84 \%$ de $\mathrm{K}$; de $83 \% \mathrm{Ca}$; de $81 \% \mathrm{Mg}$; e de $89 \%$ para $\mathrm{S}$, comparando-se a soja livre da convivência com aquela mantida em convivência com 16 plantas de E. heterophylla por vaso.

$\mathrm{O}$ acúmulo de nutrientes em plantas jovens de café em convivência com plantas daninhas (Digitaria horizontalis, Brachiaria decumbens, Brachiaria plantaginea e Mucuna aterrima) cultivadas em competição por um período de 90 dias, em quatro densidades de infestação (zero, duas, quatro e seis plantas por vaso), proporcionou menor teor de nutrientes nas folhas (N, P, K, Ca, Mg e S). Este efeito foi acentuado conforme o incremento da densidade de plantas, exceto para as concentrações de $\mathrm{N}$ nas folhas do cafeeiro que conviveram com $M$. aterrima (FIALHO et al., 2012). Ronchi et al., (2003) avaliando os efeitos da interferência, de sete espécies de plantas daninhas no conteúdo relativo (CR) de macro e micronutrientes de plantas de café, mesmo em baixas densidades, observaram decréscimos consideráveis no conteúdo relativo de nutrientes, principalmente na presença de $B$. pilosa, $C$. diffusa, L. sibiricus e $R$. brasiliensis. O grau de interferência variou de acordo com a espécie e a densidade das plantas daninhas. B. pilosa foi a planta daninha que extraiu a maior quantidade de nutrientes do solo, promovendo redução no conteúdo relativo da parte aérea de café de $66 \%$ de N, $46 \%$ de P, $58 \%$ de K, $59 \%$ de $\mathrm{Ca}, 52 \%$ de $\mathrm{Mg}$ e $41 \%$ de $\mathrm{S}$ na densidade de três plantas daninhas por vaso em relação à testemunha.

\section{Conclusões}

As plantas daninhas $C$. benghalensis, E. indica, $U$. brizantha e $U$. ruziziensis apresentam maior potencial de competição, sendo responsáveis pelos maiores efeitos na produtividade e nas características qualitativas dos grãos.

\section{Referências Bibliográficas}

AGOSTINETTO, D.; FLECK, N. G.; RIZZARDI, M. A.; JUNIOR MEROTTO, A.; VIDAL, R. A. Arroz vermelho: ecofisiologia e estratégias de controle. Ciência Rural, Santa Maria-RS, v. 31, n. 2, p. 341-349, 2001.

BHAN, V.; KUKULA, S. Weeds and their control in chickpea. In: M. C. SAXENA; K. B. SINGH (Eds.). The chickpea. Wallingford: CAB International, 1987. p. 319-328.

BRAZACA, S. G.; SILVA, F. C. Enhancers and inhibitors of iron availability in legumes. Plant Foods for Human Nutrition, Londres, v. 58, n. 3, p. 1-8, 2003.

BRIDGES, D. C.; BRECKE, B. J.; BARBOUR, J. C. Wild poinsettia (Euphorbia heterophylla) interference with peanut (Arachis hypogaea). Weed Science, Washington, v. 40, n. 1, p. 37-42, 1992.

CARVALHO, L. B., BIANCO, S.; GUZZO, C. D. Interferência de Euphorbia heterophylla no crescimento e acúmulo de macronutrientes da soja. Planta Daninha, ViçosaMG, v. 28, n. 1, p. 33-39, 2010.

CERNA, L.; VALDEZ, V. Influencia de las poblaciones de las malezas Sorghum halepense y Bidens pilosa sobre el redimiento de frijol (Phaseolus vulgaris L.)" Pirata 2. Revista Interamericana de Ciências Agrícolas, Turrialba, v. 37, n. 4, p. 303-309, 1987.

DETMANN, E; VALADARES FILHO, S. C. On the estimation of non-fibrous carbohydrates in feeds and diets. Arquivo Brasileiro de Medicina Veterinária e Zootecnia, Belo Horizonte-MG, v. 62, n. 4, p. 980-984, 2010.

EMBRAPA. EMPRESA BRASILEIRA DE PESQUISA AGROPECUÁRIA. Manual de métodos de análises de solo. 2 ed. Rio de Janeiro-RJ: Ministério da Agricultura e do Abastecimento. 1997. 212p.

FAOSTAT. FOOD AND AGRICULTURE ORGANIZATION. Statistical Year Book. New York-USA, v. 59, n. 16, 2016. 388 p. Disponível em: <http://www.faostat.fao.org.br> Acesso em 10 set. 2016.

FERREIRA, A. C. P.; BRAZACA, S. G. C.; ARTHUR, V. Alterações químicas e nutricionais do grão-de-bico (Cicer arietinum L.) cru irradiado e submetido à cocção. Ciência $\mathbf{e}$ Tecnologia de Alimentos, Campinas-SP, v. 26, n. 1, p. 80-88, 2006.

FIALHO, C. M. T.; SILVA, A. A.; FARIA, A. T.; TORRES, L. G.; ROCHA, P. R. R.; SANTOS, J. B. Teor foliar de nutrientes em plantas daninhas e de café cultivadas em competição. Planta Daninha, Viçosa-MG, v. 30, n. 1, p. 6573, 2012.

FREITAS, F. C. L.; MEDEIROS, V. F. L. P.; GRANGEIRO, L. C.; SILVA, M. G. O.; NASCIMENTO, P. G. M. L.; NUNES, G. H. Interferência de plantas daninhas na cultura do feijão-caupi. Planta Daninha, Viçosa-MG, v. 27, n. 2, p. 241247,2009

HOSSAIN，S.; FORD，R.; MCNEIL，D.; PITTOCK，C.; PANOZZO, J. F. Inheritance of seed size in chickpea (Cicer arietinum L.) and identification of QTL based on 100-seed 
weight and seed size index. Australian Journal of Crop Science, Sydney, v. 4, n. 2, p. 126-135, 2010.

IBGE. INSTITUTO BRASILEIRO DE GEOGRAFIA E ESTATÍSTICA. Tabelas de composição de alimentos. 4. ed. Rio de Janeiro-RJ: Centro de Documentação e Disseminação de Informações, 1996. p. 24-36.

JORGENSEN, S. S. Metodologia utilizada para análises químicas de rotina: guia analítico. Piracicaba-SP: CENA. 1977. 24p.

KJELDAHL, J. G. C. T. Neue methode zur bestimmung des stickstoffs in organischen körpern. Fresenius' Journal of Analytical Chemistry, New York, v. 22, n. 1, p. 366-382, 1984.

RONCHI, C. P.; TERRA, A. A.; SILVA. A. A.; FERREIRA, L. R. Acúmulo de nutrientes pelo cafeeiro sob interferência de plantas daninhas. Planta Daninha, Viçosa-MG, v. 21, n. 2, p. 219-227, 2003.

SANTOS, A. B.; FAGERIA, N. K.; SILVA, O. F.; MELO, M. L. B. Resposta do feijoeiro ao manejo de nitrogênio em várzeas tropicais. Pesquisa Agropecuária Brasileira, Brasília-DF, v. 38, n. 11, p. 1265-1271, 2003.
SILVA, A. F.; FERREIRA, E. A.; CONCENÇO, G.; FERREIRA, F. A.; ASPIAZU, I.; GALON, L.; SEDIYAMA, T.; SILVA, A. A. Densidades de plantas daninhas e épocas de controle sobre os componentes de produção da soja. Planta Daninha, Viçosa-MG, v. 26, n. 1, p. 65-71, 2008.

VAN DER MAESEN, L. J. G. Taxonomy, distribution and evolution of the chickpea and its wild relatives. In: WITCOMBE, J. R., ERSKINE, W. (Ed.) Genetic resources and their exploitation - chickpeas, faba beans and lentils. 6 . ed. Washington: Springer Science. 1984. p. 95-104.

WHISH, J. P. M.; SINDEL, B. M.; JESSOP, R. S.; FELTON, W. L. The effect of row spacing and weed density on yield loss of chickpea. Crop and Pasture Science, Australia, v. 53, n. 12 , p. $1335-1340,2002$

WILLIAMS, P. C.; SINGH, U. Nutritional quality and the evaluation of quality in breeding programmes. In: SAXENA, M. C.; SINGH, K. B. (Ed.) The chickpea. Wallingford: CAB International. 1987. p. 329-356.

ZANATTA, J. F.; FIGUEREDO, S.; FONTANA, L. C.; PROCÓPIO, S. O. Interferência De Plantas Daninhas em Culturas Olerícolas. Revista da Faculdade de Zootecnia, Veterinária e Agronomia, Uruguaiana-RS, v. 13, n. 2, p. 3957, 2006. 